YURIE DIAS, Patricia. A relação entre estado e as entidades privadas na regulação do comércio internacional por meio dos regulamentos e padrões privados. Revista Eletrônica Direito e Política, Programa de Pós-Graduação Stricto Sensu em Ciência Jurídica da UNIVALI, Itajaí, v.16, n.1, ${ }^{0}$ quadrimestre de 2021. Disponível em: www.univali.br/direitoepolitica - ISSN 1980-7791

\title{
A RELAÇÃO ENTRE ESTADO E AS ENTIDADES PRIVADAS NA REGULAÇÃO DO COMÉRCIO INTERNACIONAL POR MEIO DOS REGULAMENTOS E PADRÕES PRIVADOS
}

\author{
THE RELATIONSHIP BETWEEN THE STATE AND PRIVATE ENTITIES IN THE \\ REGULATION OF INTERNATIONAL TRADE THROUGH PRIVATE REGULATIONS AND \\ STANDARDS
}

Patricia Yurie Dias ${ }^{1}$

\section{RESUMO}

O trabalho analisa o papel complementar dos regulamentos e padrões privados dos Estados e das entidades não estatais às regras da Organização Mundial do Comércio (OMC) com o intuito de gerar maior segurança e qualidade para os produtos no âmbito do comércio internacional. A OMC visa promover a liberalização e eliminação da discriminação do comércio internacional. Dessa forma, por meio do estudo de alguns casos submetidos ao Órgão de Solução de Controvérsias (OSC) da OMC, em que pese a maioria dos casos submetidos ao OSC terem tido desfechos distintos, constatou-se que os padrões privados podem complementar as regras da OMC, desde que não sejam medidas protecionistas disfarçadas de barreiras não tarifárias ao comércio internacional.

PALAVRAS-CHAVE: Direito Internacional; Jurisdição Internacional; Padrões privados; Comércio Internacional; OMC.

\begin{abstract}
The paper examines the complementary role of the private regulations and standards of States and non-state entities to the rules of the World Trade Organization (WTO) in order to promote safety and quality for products in the scope of international trade. The WTO aims to promote the liberalization and elimination of discrimination in international trade. Thus, through the study of some cases submitted to the WTO Dispute Settlement Body (DSB), despite the fact that most cases submitted to the DSB had different conclusions, it was found that private standards can complement the rules of the WTO, if they are not protectionist measures disguised as non-tariff barriers to international trade.
\end{abstract}

KEYWORDS: International Law; International Jurisdiction; Private Standards; International Trade; WTO.

\footnotetext{
1 Mestranda em Direito pelo Centro Universitário de Brasília - UniCeub desde 2018, Brasília, Distrito Federal, Brasil. Graduada em Direito (2007) e Relações Internacionais (2003) pelo UniCeub e em Ciências Sociais pela Universidade de Brasília - UnB (2004). Email: patriciaydias@gmail.com . Currículo lattes: http://lattes.cnpq.br/7606000551626183.
} 
YURIE DIAS, Patricia. A relação entre estado e as entidades privadas na regulação do comércio internacional por meio dos regulamentos e padrões privados. Revista Eletrônica Direito e Política, Programa de Pós-Graduação Stricto Sensu em Ciência Jurídica da UNIVALI, Itajaí, v.16, n.1, ${ }^{0}$ quadrimestre de 2021. Disponível em: www.univali.br/direitoepolitica - ISSN 1980-7791

\section{INTRODUÇÃO}

Atualmente, no âmbito do comércio internacional, os países e as empresas têm utilizado regulamentos e padrões privados para os produtos e processos de produção com o intuito de garantir maior segurança e qualidade dos produtos, bem como preservar o meio ambiente, promover a sustentabilidade e proteger a saúde humana, animal e vegetal.

A OMC é uma organização internacional que lida com as regras do comércio entre os países membros. Um dos principais objetivos da OMC é a liberalização do comércio, por meio da diminuição das barreiras tarifárias e da eliminação da discriminação no comércio. Contudo, verifica-se que o OSC da OMC tem sido questionado acerca da imposição de alguns regulamentos e padrões privados que podem ser medidas disfarçadas de barreiras não tarifárias ao comércio internacional.

Nesse sentido, os objetivos do artigo são: estudar algumas normas e padrões privados estabelecidos pelas empresas e organizações não governamentais; bem como examinar alguns casos submetidos ao órgão de solução de controvérsias da OMC que decidiu responsabilizar ou não o Estado pela imposição na adoção de certos padrões internacionais. Neste estudo, optou-se analisar os seguintes casos²: DS458: Austrália-Tabaco, DS369: Comunidades Europeias-Foca e DS284: México-Feijão Preto.

Dessa forma, o problema desse trabalho é verificar se os padrões privados complementam as regras multilaterais da OMC no sentido de gerar maior segurança e qualidade para os produtos, bem como preservar o meio ambiente,

\footnotetext{
${ }^{2}$ A pesquisa dos casos ocorreu a partir da lista cronológica das disputas submetidas à OMC, disponível no site: https://www.wto.org/english/tratop_e/dispu_e/dispu_status_e.htm. Acesso em 15 ago. 2019. De acordo com a lista cronológica, até $22 / 08 / 2019$ as disputas totais submetidas eram de DS1 $(10 / 1 / 1995)$ à DS586 (5/07/2019). Diante de todos esses casos, foi realizada uma segunda pesquisa a partir do termo de pesquisa "certain measures" o que correspondeu à 52 casos. Dentre esses 52 casos, escolheu-se analisar 3 casos relacionados com "padrões privados" que já tinham uma decisão definitiva do OSC, ou seja, tinham o seguinte andamento processual: "implementation notified by respondent", "settled or terminated (withdrawn, mutually agreed solution)"e "report(s) adopted".
} 
YURIE DIAS, Patricia. A relação entre estado e as entidades privadas na regulação do comércio internacional por meio dos regulamentos e padrões privados. Revista Eletrônica Direito e Política, Programa de Pós-Graduação Stricto Sensu em Ciência Jurídica da UNIVALI, Itajaí, v.16, n.1, ${ }^{0}$ quadrimestre de 2021. Disponível em: www.univali.br/direitoepolitica - ISSN 1980-7791

proteger a saúde humana, animal e vegetal ao lado da promoção do comércio internacional entre os países.

A hipótese do artigo é que os países, as empresas privadas e os entes não governamentais podem criar normas e padrões privados para os produtos com o intuito de gerar maior segurança e qualidade para os produtos complementando assim as regras multilaterais da OMC. Por outro lado, sabe-se que estes mesmos atores podem criar normas e padrões privados como forma de medidas protecionistas das empresas locais.

Assim, para analisar se os padrões privados complementam as regras multilaterais da OMC, o método indutivo de pesquisa é baseado na análise bibliográfica (normas e jurisprudências), bem como por meio da coleta dos dados de forma qualitativa para alcançar os resultados previstos.

Por fim, o artigo é composto pelos seguintes tópicos: o papel da OMC no comércio internacional, os padrões privados como normas complementares às regras da OMC, os padrões privados disfarçados de medidas protecionistas e os casos submetidos ao órgão de solução de controvérsias da OMC.

\section{O PAPEL DA OMC NO COMÉRCIO INTERNACIONAL}

A OMC começou a funcionar em 1 de janeiro de 1995 e tem se destacado pelo seu mecanismo de soluções de controvérsias no âmbito do comércio internacional. Contudo, a OMC não apareceu de imediato, pois a primeira tentativa foi a criação de uma Organização Internacional do Comércio (OIC) em 1946 com o intuito de completar o sistema de Bretton Woods já formado pelo Banco Mundial e Fundo Monetário Internacional (FMI). A OIC não teve sucesso, deixando uma lacuna no sistema de instituições econômicas internacionais de Bretton Woods ${ }^{3}$.

\footnotetext{
3 BOSSCHE, Peter Van Den. Curso de Solução de Disputas em Comércio Internacional, Investimentos e Propriedade Intelectual. Nações Unidas: Conferência das Nações Unidas sobre Comércio e Desenvolvimento (UNCTAD), 2003, p. 7.
} 
YURIE DIAS, Patricia. A relação entre estado e as entidades privadas na regulação do comércio internacional por meio dos regulamentos e padrões privados. Revista Eletrônica Direito e Política, Programa de Pós-Graduação Stricto Sensu em Ciência Jurídica da UNIVALI, Itajaí, v.16, n.1, ${ }^{0}$ quadrimestre de 2021. Disponível em: www.univali.br/direitoepolitica - ISSN 1980-7791

Assim, no lugar da OIC criou-se o Acordo Geral sobre Tarifas e Comércio (GATT1947). O GATT-1947 não tinha regras acerca de um sistema de solução de controvérsias entre as partes e, os conflitos eram resolvidos por meio de negociações diplomáticas, recomendações ou painéis que apresentavam os relatórios sugeridos pelos grupos de trabalho ${ }^{4}$.

O GATT era um mero tratado multilateral, não uma organização. O rascunho da Carta de OMC terminou em 1948, mas nunca entrou em vigor, pois não houve aprovação do Congresso dos Estados Unidos. O Protocolo de Aplicação Provisório (PPA) do GATT foi reconhecido como um tratado obrigatório pelo direito internacional, contudo, em que pese as inúmeras tentativas em tornar o PPA definitivo, nenhuma delas obteve sucesso e muitas vezes os países justificavam suas ações com bases em interesses nacionais em detrimento do comércio internacional ${ }^{5}$.

Somente com a Rodada do Uruguai (1986 a 1993) as partes do GATT começaram as negociações para a liberalização do comércio internacional e demonstraram a manifestação acerca da necessidade de se criar uma organização do comércio. Assim, em 1994 foi assinado o Acordo Constitutivo da OMC em Marraqueche; e em 1995, a OMC começou a funcionar6.

De acordo com o preâmbulo do Acordo da OMC, a organização visa não só a liberalização do comércio, mas também a proteção do meio ambiente por meio do desenvolvimento sustentável, a inserção dos países menos desenvolvidos no comércio mundial, a diminuição das barreiras tarifárias e a eliminação da discriminação no comércio. Ressalta-se que as principais funções da OMC são: implementar os acordos da organização, estabelecer forum para as negociações comerciais, ter um mecanismo de solução de controvérsias, monitorar as políticas

\footnotetext{
${ }^{4}$ BARRAL, Welber. Solução de controvérsias na OMC. In: KLOR et al. Solução de Controvérsias: OMC, União Europeia e Mercosul. Rio de Janeiro: Konrad-Adenauer-Stiftung, 2004, p. 13. 5 JACKSON, John Howard. The world trading system: law and policy of international economic relations. 2. ed. Cambridge: MIT Press, 1997, p. 37.

6 BOSSCHE, Peter Van Den. Curso de Solução de Disputas em Comércio Internacional, Investimentos e Propriedade Intelectual, p. 8.
} 
YURIE DIAS, Patricia. A relação entre estado e as entidades privadas na regulação do comércio internacional por meio dos regulamentos e padrões privados. Revista Eletrônica Direito e Política, Programa de Pós-Graduação Stricto Sensu em Ciência Jurídica da UNIVALI, Itajaí, v.16, n.1, ${ }^{0}$ quadrimestre de 2021. Disponível em: www.univali.br/direitoepolitica - ISSN 1980-7791

comerciais e por fim, cooperar com outras organizações internacionais e não governamentais ${ }^{7}$.

Dessa forma, cabe frisar que, em que pese o papel importante da OMC na busca de um comércio internacional mais justo entre os países, uma das principais questões levantadas pelos estudiosos é se as instituições nacionais e internacionais têm a capacidade de lidar com os desafios advindos das práticas injustas no comércio ${ }^{8}$.

Pois, se de um lado, tem a OMC defendendo o livre comércio, por outro, tem países adotando medidas protecionistas nas suas práticas comerciais. Ao longo dos anos, o comércio e o protecionismo sempre andaram juntos, mesmo que de forma antagônica, ou seja, uns períodos eram focados mais na liberdade comercial, outros na proteção das indústrias nacionais ${ }^{9}$.

Desta maneira, verifica-se que, no âmbito do comércio internacional, a OMC tem sido uma organização bastante utilizada nas questões relacionadas ao comércio, bem como sobre temas ligados com o meio ambiente, as medidas sanitárias e fitossanitárias, a propriedade intelectual e os investimentos; se tornando um locus de governança em diversos temas relacionados ao comércio ${ }^{10}$.

\section{OS PADRÕES PRIVADOS COMO NORMAS COMPLEMENTARES ÀS REGRAS DA OMC}

O comércio internacional é marcado pela utilização de regulamentos e padrões privados pelos países e empresas. Ressalta-se que a criação de tais normas e padrões advém da conscientização social quanto à importância da segurança e da

\footnotetext{
7 BOSSCHE, Peter Van Den. Curso de Solução de Disputas em Comércio Internacional, Investimentos e Propriedade Intelectual, p. 12.

8 JACKSON, John Howard. The world trading system: law and policy of international economic relations, p. 49.

9 PIFFER, Carla. Comércio Internacional e Meio Ambiente: A Organização Mundial do Comércio como locus de governança ambiental. Veredas do Direito, Belo Horizonte, v.8, n.15, Jan/Jun. 2011. p. 112.

10 PIFFER, Carla. Comércio Internacional e Meio Ambiente: A Organização Mundial do Comércio como locus de governança ambiental, p. 113.
} 
YURIE DIAS, Patricia. A relação entre estado e as entidades privadas na regulação do comércio internacional por meio dos regulamentos e padrões privados. Revista Eletrônica Direito e Política, Programa de Pós-Graduação Stricto Sensu em Ciência Jurídica da UNIVALI, Itajaí, v.16, n.1, ${ }^{0}$ quadrimestre de 2021. Disponível em: www.univali.br/direitoepolitica - ISSN 1980-7791

qualidade dos produtos. Os instrumentos que estabelecem requisitos para os métodos e processos de produção podem ser classificados em dois tipos: regulamentos e padrões/normas técnicas, conforme a seguir:

Os primeiros consistem em exigência do governo, por meio de um regulamento, uma portaria ou um decreto, e, portanto, são obrigatórios. Os segundos provêm, muitas vezes, da demanda do próprio mercado de estabelecer requisitos mínimos de qualidade, segurança, sustentabilidade, entre outros, a fim de alcançar maior padronização dos produtos e, em princípio, facilitar o comércio. Esses padrões são estabelecidos por meio de normas técnicas de observância voluntária, que podem ser elaboradas por entidades privadas ou por entidades reconhecidas pelo governo como organismo normalizador nacional, a exemplo da Associação Brasileira de Normas Técnicas (ABNT), no caso brasileiro ${ }^{11}$.

À primeira vista, os requisitos técnicos para produtos e métodos de processos de produção estabelecidos pelos entes privados podem ser vistos como se fossem barreiras não tarifárias ao comércio. Contudo, por não serem impostos pelo Estado ou pela OMC não são obrigatórios; mas sim, exigências do mercado. Nesse sentido, percebe-se que os entes não estatais, por meio da criação de exigências técnicas, passaram a complementar a atividade de regulação do Estado. Este papel é conhecido como "privatização da governança"12.

É importante ressaltar que, enquanto a governabilidade está relacionada com o sistema político-institucional, a governança engloba a sociedade como um todo buscando atender as demandas sociais. Assim, além do governo, outros atores atuam no desenvolvimento social, como as organizações supranacionais, Organizações Não-Governamentais (ONG), empresas multinacionais ${ }^{13}$.

No âmbito da governança do comércio, a OMC tem se destacado como um metaregulador, principalmente, com relação a regulação dos padrões privados

\footnotetext{
11 AMARAL, Manuela. Protecionismo privado: a atuação da sociedade civil na regulação do comércio internacional. Contexto Internacional (PUC), Rio de Janeiro, v. 36, n. 1, jan/jun. 2014. p. 202.

12 AMARAL, Manuela. Padrões Privados e a Atuação ou Omissão do Estado: Protecionismo

Público-Privado? Contexto Internacional (PUC), Rio de Janeiro, v. 37, n. 2, mai/ago. 2015, p. 403.

${ }^{13}$ PIFFER, Carla. Comércio Internacional e Meio Ambiente: A Organização Mundial do Comércio como locus de governança ambiental, p. 120.
} 
YURIE DIAS, Patricia. A relação entre estado e as entidades privadas na regulação do comércio internacional por meio dos regulamentos e padrões privados. Revista Eletrônica Direito e Política, Programa de Pós-Graduação Stricto Sensu em Ciência Jurídica da UNIVALI, Itajaí, v.16, n.1, ${ }^{0}$ quadrimestre de 2021. Disponível em: www.univali.br/direitoepolitica - ISSN 1980-7791

elaborados por empresas privadas ou $\mathrm{ONG}^{14}$. Ou seja, quando os países membros questionam se determinados regulamentos ou padrões privados violam os acordos da OMC, estes padrões privados são analisados com base nas regras multilaterais da OMC, destacando-se o Acordo de Medidas Sanitárias e Fitossanitárias (Acordo SPS $)^{15}$ relacionado com a segurança dos alimentos e a saúde dos animais e das plantas e o Acordo sobre Barreiras Técnicas ao Comércio (Acordo TBT) ${ }^{16}$ acerca da normalização e procedimentos de avaliação de conformidade com regulamentos técnicos e normas.

Dessa forma, verifica-se que a criação de regulamentos e padrões privados são formas de se regular determinado setor na economia por meio de procedimentos ou técnicas necessárias a serem seguidas pelas empresas ou governos. A criação de determinados padrões privados visa proteger algum interesse social que pode ser segurança dos produtos, direitos humanos, meio ambiente, direitos trabalhistas, saúde humana e animal.

A regulação é o processo de ordenamento social e pode ser realizada pelo governo por meio de incentivos (subsídios), punições e instituições (contratos); ou delegada às organizações intergovernamentais (Organização para Cooperação e Desenvolvimento Econômico - OCDE, Fundo das Nações Unidas para a Infância UNICEF, FMI, Organização Mundial da Saúde - OMS). O governo também pode delegar a regulação por omissão, ou seja, deixa lacunas para que atores não estatais atuem na regulação. Essa omissão é uma decisão política. Assim, os padrões podem ser criados por ONG (Comissão do Codex Alimentarius - Codex, International Standardization Body - ISO) ou mesmo entes privados ${ }^{17}$.

\footnotetext{
${ }^{14}$ MAVROIDIS, Petros C. e WOLFE, Robert. Private Standards and the WTO: Reclusive No More. EUI Working Paper RSCAS 2016/17. European University Institute. Robert Schuman Centre for Advanced Studies. Global Governance Programme. 2016, p. 1.

15 BRASIL. Ministério da Economia. Acordo SPS. Disponível em: http://www.mdic.gov.br/index.php/comercio-exterior/negociacoes-internacionais/1885-omcacordos-da-omc Acesso em: 20 mar 2020.

16 BRASIL. Ministério da Economia. Acordo TBT. Disponível em: http://www.mdic.gov.br/index.php/comercio-exterior/negociacoes-internacionais/1885-omcacordos-da-omc Acesso em: 20 mar 2020.

17 MAVROIDIS, Petros C. e WOLFE, Robert. Private Standards and the WTO: Reclusive No More, p. 1.
} 
YURIE DIAS, Patricia. A relação entre estado e as entidades privadas na regulação do comércio internacional por meio dos regulamentos e padrões privados. Revista Eletrônica Direito e Política, Programa de Pós-Graduação Stricto Sensu em Ciência Jurídica da UNIVALI, Itajaí, v.16, n.1, ${ }^{0}$ quadrimestre de 2021. Disponível em: www.univali.br/direitoepolitica - ISSN 1980-7791

Como dito, a regulação do governo visa influenciar o comportamento privado do indivíduo para agir ou deixar de agir de determinada forma. Nesse sentido, as medidas governamentais podem apresentar diferentes tipos de comportamentos que será escolhido pelo ente estatal como: melhores condições para comercialização, redução de impostos, dentre outros ${ }^{18}$. Em suma, apesar de não se tratar de situações dentro das controvérsias submetidas à OMC, cabe demonstrar dois casos, a título de exemplo, que confirmam a ampla utilização de padrões privados pelas empresas e países. O primeiro exemplo é o das Nações Unidas com o United Nations Global Compact ${ }^{19}$ e o seu guia empresarial e para direitos humanos que visa promover e respeitar os direitos humanos e o ambiente entre a comunidade de empresários internacionais mesmo que os documentos mostram que formalmente não existem obrigações legais internacionais para se fazer isso ${ }^{20}$.

Outro exemplo da inserção de padrões privados aderido por empresas transnacionais ocorre no caso do comércio internacional dos diamantes. A exploração dos diamantes sempre foi marcada por conflitos armados, lutas sangrentas, exploração infantil e de mulheres, principalmente, nos países africanos como Angola e Libéria. Contudo, ao longo dos anos, grupos de interesses públicos, ONU, estados individuais e indústria do diamante instituíram o processo Kimberley ${ }^{21}$, em 2000, para prevenir que os diamantes advindos de conflitos armados entrassem no mercado 22 . Assim, as empresas aderiram a uma certificação de forma voluntária, pois no início não existia uma obrigação legal

\footnotetext{
18 AMARAL, Manuela. Padrões Privados e a Atuação ou Omissão do Estado: Protecionismo Público-Privado?, p. 405.

19 O United Nations Global Compact é um Pacto Global proposta pela Organização das Nações Unidas para encorajar as empresas a adotarem princípios de sustentabilidade, responsabilidade social, direitos humanos, direitos trabalhistas, meio ambiente e anti-corrupção. Disponível em: https://www.unglobalcompact.org/ Acesso em: 12 abr. 2020.

${ }^{20}$ KOLIEB, Jonathan. When to Punish, When to Persuade and When to Reward: Strengthening Responsive Regulation with the Regulatory Diamond. Monash University Law Review, 2015, p. 156.

${ }^{21}$ O Processo Kimberley é um compromisso para erradicar os conflitos de diamantes no mundo por meio a união entre governos, sociedade civil $e$ as indústrias. Disponível em: https://www.kimberleyprocess.com/en/what-kp Acesso em: 12 abr. 2020.

${ }^{22}$ KOLIEB, Jonathan. When to Punish, When to Persuade and When to Reward: Strengthening Responsive Regulation with the Regulatory Diamond, p. 156.
} 
YURIE DIAS, Patricia. A relação entre estado e as entidades privadas na regulação do comércio internacional por meio dos regulamentos e padrões privados. Revista Eletrônica Direito e Política, Programa de Pós-Graduação Stricto Sensu em Ciência Jurídica da UNIVALI, Itajaí, v.16, n.1, ${ }^{0}$ quadrimestre de 2021. Disponível em: www.univali.br/direitoepolitica - ISSN 1980-7791

doméstica. No âmbito do Brasil, o Certificado do Processo Kimberley ${ }^{23}$ foi implantado no país em 2003, por meio da Lei no 10.743, de 09/10/03.

A International Standardization Body (ISO) ${ }^{24}$ é uma organização não governamental, responsável por gerar uma classe mundial de especificações para produtos, serviços e sistemas para garantir a qualidade, segurança e eficiência, ou seja, é um instrumento facilitador do comércio mundial. Em 17/04/2020, constatou-se no site da ISO a informação de 23.144 padrões internacionais e documentos relacionados com indústria, tecnologia, alimentação, segurança alimentar, agricultura e saúde. Em que pese a legitimidade do ator privado atuar no ambiente internacional ser controversa, a OMC tem reconhecido os padrões emitidos pela ISO (Anexo I do TBT). Nesse sentido, percebe-se a influência dessa organização além das fronteiras ${ }^{25}$.

Os temas relacionados com a segurança e a qualidade dos produtos, bem como questões ambientais e direitos humanos têm sido debatidos pelos governos e sociedade civil. Tais discussões podem contribuir para a criação de regulamentos e padrões favorecendo melhores práticas no comércio internacional ou podem gerar barreiras ao comércio. O objetivo central da discussão é encontrar o ponto de equilíbrio entre a proteção desses interesses e a não criação de medidas discriminatórias ao comércio internacional ${ }^{26}$.

Neste contexto, infere-se que permitir a inserção de padrões de comportamentos não legais é apropriada, especialmente quando se considera a multiplicidade de

23 BRASIL. Agência Nacional de Mineração. O Sistema de Certificação do Processo de Kimberley (SCPK) é um mecanismo internacional que visa evitar que diamantes ilegais possam financiar conflitos armados e desacreditar o mercado legítimo de diamantes brutos. Disponível em: http://www.anm.gov.br/assuntos/ao-minerador/certificado-do-processo-de-kimberley Acesso em: 12 abr. 2020.

${ }^{24}$ ISO. Disponível em: https://www.iso.org/home.html . Acesso em: 17 abr. 2020.

${ }^{25}$ BADIN, Michelle Ratton Sanchez; TAKITANI, Marina Yoshimi. Um estranho no ninho? Padrões privados no Acordo de Barreiras Técnicas ao Comércio da OMC. Revista de Direito Internacional, Brasília, v. 13, n. 3, 2016. p. 199.

26 AMARAL, Manuela. Protecionismo privado: a atuação da sociedade civil na regulação do comércio internacional, p. 202. 
YURIE DIAS, Patricia. A relação entre estado e as entidades privadas na regulação do comércio internacional por meio dos regulamentos e padrões privados. Revista Eletrônica Direito e Política, Programa de Pós-Graduação Stricto Sensu em Ciência Jurídica da UNIVALI, Itajaí, v.16, n.1, ${ }^{0}$ quadrimestre de 2021. Disponível em: www.univali.br/direitoepolitica - ISSN 1980-7791

atores não governamentais que atuam como reguladores em vários contextos contemporâneos ${ }^{27}$.

Um estudo elaborado pela Organização das Nações Unidas para Agricultura (FAO) demonstrou que os interesses privados estabelecidos pelos padrões privados estão em consonância com os interesses públicos e podem contribuir com a implementação das políticas públicas, ou seja, a governança do mercado pode operar ao lado das políticas governamentais ${ }^{28}$.

Assim, percebe-se que no direito internacional, os mecanismos de regulação entre estado, indústria e sociedade civil são voltados para a compliance, onde as empresas transnacionais buscam adotar padrões, além das suas leis domésticas como forma de internacionalizar os compromissos internacionais ${ }^{29}$.

Dessa maneira, no que tange aos padrões e às normas privados verifica-se que eles são relevantes não só para o comércio internacional, mas também para a OMC, principalmente, quando estão relacionados com os dispositivos do Acordo SPS e do Acordo TBT.

\section{OS PADRÕES PRIVADOS DISFARÇADOS DE MEDIDAS PROTECIONISTAS}

Se por um lado, os regulamentos e padrões privados, a princípio, são criados para gerar maior segurança para os processos de produção; por outro, em alguns casos demonstram que a implantação dessas normas técnicas pode criar barreiras desnecessárias ao comércio internacional. Por isso, os países membros da OMC, diante de algumas imposições de regulamentos e padrões privados, submetem os casos ao Órgão de Solução de Controvérsias da OMC para verificar se tais padrões

\footnotetext{
27 KOLIEB, Jonathan. When to Punish, When to Persuade and When to Reward: Strengthening Responsive Regulation with the Regulatory Diamond, p. 144.

28 AMARAL, Manuela. Padrões Privados e a Atuação ou Omissão do Estado: Protecionismo Público-Privado?, p. 404.

${ }^{29}$ KOLIEB, Jonathan. When to Punish, When to Persuade and When to Reward: Strengthening Responsive Regulation with the Regulatory Diamond, p. 156.
} 
YURIE DIAS, Patricia. A relação entre estado e as entidades privadas na regulação do comércio internacional por meio dos regulamentos e padrões privados. Revista Eletrônica Direito e Política, Programa de Pós-Graduação Stricto Sensu em Ciência Jurídica da UNIVALI, Itajaí, v.16, n.1, ${ }^{0}$ quadrimestre de 2021. Disponível em: www.univali.br/direitoepolitica - ISSN 1980-7791

podem ser medidas protecionistas disfarçadas de barreiras não tarifárias ao comércio internacional.

A OMC possui acordos voltados para regular as barreiras técnicas e medidas sanitárias e fitossanitárias permitidas na organização multilateral. Tais acordos buscam evitar obstáculos e práticas injustas no comércio internacional. Contudo, os padrões privados são um novo desafio para OMC onde as regras multilaterais são aplicáveis somente aos países membros, o que não inclui as normas elaboradas por entes não estatais ou privados. Assim, os padrões privados, a princípio, parecem estar fora do alcance da OMC, mesmo quando parecem ser barreiras ao comércio. A análise acerca das medidas do Estado ou de entes não estatais devem ser avaliados com cautela, tendo em vista que dentro da OMC a interpretação pode variar a depender de qual ator impôs a medida restritiva ao comércio, se foi um ente estatal ou não, bem como qual o real objetivo a ser alcançado pela medida ${ }^{30}$.

No caso do meio ambiente, a OMC tem se destacado na governança do comércio e meio ambiente. Apesar de existir regulações ambientais, elas são reconhecidas como princípios, não tendo nenhuma fiscalização ou vinculação obrigatória ${ }^{31}$. Contudo, um ponto importante acerca do problema ambiental é o impacto transfronteiriço, uma vez que a ação de um país pode refletir em outro.

Assim, a discussão gira em torno dos que defendem o livre comércio e dos ambientalistas. Enquanto os primeiros defendem a liberalização do comércio; os segundos visam a proteção do meio ambiente, saúde humana, proteção do consumidor e animais. Dessa maneira, por haver grupos bem opostos, os governos sofrem pressões de ambos os lados e, quando buscam implementar as políticas públicas em prol do meio ambiente, de certa maneira, tais medidas refletem no

\footnotetext{
30 AMARAL, Manuela. Protecionismo privado: a atuação da sociedade civil na regulação do comércio internacional, p. 202.

${ }^{31}$ PIFFER, Carla. Comércio Internacional e Meio Ambiente: A Organização Mundial do Comércio como locus de governança ambiental, p. 123.
} 
YURIE DIAS, Patricia. A relação entre estado e as entidades privadas na regulação do comércio internacional por meio dos regulamentos e padrões privados. Revista Eletrônica Direito e Política, Programa de Pós-Graduação Stricto Sensu em Ciência Jurídica da UNIVALI, Itajaí, v.16, n.1, ${ }^{0}$ quadrimestre de 2021. Disponível em: www.univali.br/direitoepolitica - ISSN 1980-7791

comércio, pois a competitividade pode ser afetada pelos padrões ambientais ao influenciar a concorrência e incentivar determinados ramos da indústria ${ }^{32}$.

Na maioria dos casos, a adesão aos padrões/normas técnicas é voluntária, ou seja, o governo não poderia restringir a importação de produtos que não estivessem em conformidade com estas especificações. Contudo, enfatiza-se que estes requisitos têm restringido o acesso aos mercados uma vez que os importadores têm exigido a implementação de certos padrões voluntários. Dessa maneira, os membros da OMC têm questionado certas medidas restritivas ao comércio estabelecidas pelo governo. Todavia, com relação às normas técnicas criadas por atores não estatais não se tem certeza o que pode ser feito na OMC quando tais medidas forem restritivas ao comércio internacional ${ }^{33}$. Cabe a regulação no comércio internacional a árdua tarefa de mensurar a finalidade dos padrões, conforme a seguir:

Diante desse novo cenário e da importância atribuída ao papel da regulação no comércio internacional, cria-se a difícil tarefa de mensurar até que ponto tais padrões (standards) - públicos e privados - são impostos por necessidade e relevância em termos de bem-estar e benefícios aos cidadãos e ao meio ambiente, ou se constituem novas formas de discriminação e, portanto, de barreiras explícitas ao comércio internacional" ${ }^{34}$.

Assim, diante das lacunas nos acordos da OMC acerca da adoção dos padrões privados e tendo em vistas as regras multilaterais da organização, logo a seguir serão estudados alguns casos submetidos ao OSC da OMC para verificar se tais medidas complementam as regras multilaterais ou restringem o acesso aos mercados criando barreiras desnecessárias ao comércio.

32 THORSTENSEN, Vera. A OMC - Organização Mundial do Comércio e as negociações sobre comércio, meio ambiente e padrões sociais. Rev. Bras. Polít. Int. 41 (2): 29-58, 1998, p. 35. 33 AMARAL, Manuela. Protecionismo privado: a atuação da sociedade civil na regulação do comércio internacional. Contexto Internacional (PUC), Rio de Janeiro, v. 36, n. 1, jan/jun. 2014. p. 203.

34 THORSTENSEN, Vera; KOTZIAS, Fernanda. Barreiras Regulatórias: um novo desafio para a governança da OMC. Centro de Estudos do Comércio Global e Investimentos EESP/FGV, 2015, p. 2. 
YURIE DIAS, Patricia. A relação entre estado e as entidades privadas na regulação do comércio internacional por meio dos regulamentos e padrões privados. Revista Eletrônica Direito e Política, Programa de Pós-Graduação Stricto Sensu em Ciência Jurídica da UNIVALI, Itajaí, v.16, n.1, ${ }^{0}$ quadrimestre de 2021. Disponível em: www.univali.br/direitoepolitica - ISSN 1980-7791

\section{CASOS SUBMETIDOS AO ÓRGÃO DE SOLUÇÃO DE CONTROVÉRSIAS DA OMC}

A OMC tem uma estrutura jurídica e normas complexas, formada por órgãos, acordos e princípios. No que tange ao sistema de controvérsias ele é formado pelo OSC composto por todos os membros da OMC. Todos os acordos da OMC são obrigatórios aos membros, com exceção dos acordos plurilaterais. Ressalta-se que o sistema de solução de controvérsias tem jurisdição para resolver qualquer conflito entre os membros que envolvam os acordos da $\mathrm{OMC}^{35}$.

No âmbito dos regulamentos e dos padrões privados, segundo as regras do GATT 1994, os países membros devem se responsabilizar pelas medidas governamentais quando estas forem incompatíveis com os Acordos da OMC, independentemente de exigirem dos entes privados a agirem ou não de determinada maneira. Contudo, como a OMC não tem regras gerais acerca da atribuição de medidas privadas ao Estado, alguns governos podem disfarçar as medidas como não governamentais, o que poderá ser atribuído ao membro da $\mathrm{OMC}^{36}$.

Registra-se que o OSC da OMC não tem o caráter somente jurídico, pois envolve o poder político e econômico dos membros. Muitas vezes é mais vantajoso estabelecer um acordo entre as partes do que se chegar a um litígio, pois o que se busca eliminar a medida prejudicial às regras do livre comércio, mais do que a responsabilidade internacional dos membros ${ }^{37}$.

Destarte, nos termos das regras multilaterais da OMC, constata-se que os padrões privados podem ser confrontados, principalmente, com relação às normas do GATT, do Acordo SPS e do Acordo TBT.

Segundo o Acordo SPS, qualquer medida sanitária ou fitossanitária, relacionada com a segurança dos alimentos, saúde animal e zoonoses e saúde vegetal, precisa

\footnotetext{
35 BARRAL, Welber. Solução de controvérsias na OMC. In: KLOR et al. Solução de Controvérsias: OMC, União Europeia e Mercosul, p. 16.

36 AMARAL, Manuela. Padrões Privados e a Atuação ou Omissão do Estado: Protecionismo Público-Privado?, p. 405.

${ }^{37}$ BARRAL, Welber. Solução de controvérsias na OMC. In: KLOR et al. Solução de Controvérsias: OMC, União Europeia e Mercosul, p. 22.
} 
YURIE DIAS, Patricia. A relação entre estado e as entidades privadas na regulação do comércio internacional por meio dos regulamentos e padrões privados. Revista Eletrônica Direito e Política, Programa de Pós-Graduação Stricto Sensu em Ciência Jurídica da UNIVALI, Itajaí, v.16, n.1, ${ }^{0}$ quadrimestre de 2021. Disponível em: www.univali.br/direitoepolitica - ISSN 1980-7791

ser baseada em normas, guias e recomendações internacionais como: Comissão do Codex Alimentarius (Codex), Escritório Internacional de Epizootias, Organizações Internacionais e regionais no contexto da Convenção Internacional sobre Proteção Vegetal; conforme disposto no Preâmbulo, Artigo 3 e Anexo A do referido acordo.

No âmbito do Acordo TBT, o acordo não menciona nenhum órgão de padronização, contudo, alguns artigos tratam de temas relacionados com os padrões privados como: artigo 2.2. (trata dos regulamentos técnicos e normas); artigo 3 (aborda a questão da adoção dos regulamentos técnicos por instituições públicas e não governamentais), artigo 4.1. (menciona o cumprimento do Código de Boa Conduta) e Anexo I (adoção do Guia ISO/IEC 2:1991). Um ponto sensível com relação a adoção do Guia ISO incorporado à OMC é com relação a vinculação do instrumento aos membros da OMC que não fazem parte da ISO $^{38}$.

Assim, diante das regras da OMC serão apresentados alguns casos analisados pelo OSC que decidiu responsabilizar ou não o Estado pela imposição na adoção de certos padrões internacionais. Neste estudo, optou-se analisar os seguintes casos: DS458: Austrália-Tabaco39, DS369: Comunidades Europeias-Foca ${ }^{40}$ e DS284: México-Feijão Preto ${ }^{41}$.

No caso DS458, em 03/05/2013, Cuba consultou a Austrália acerca de certas leis e regulações impostas que restringiam a marca comercial e outros regulamentos impostos aos produtos de tabaco. Em 04/04/2014, Cuba solicitou o estabelecimento de painel da OSC. De acordo com o painel, dentre outros achados, constatou-se que Cuba não demonstrou que as medidas australianas adotadas

\footnotetext{
38 BADIN, Michelle Ratton Sanchez; TAKITANI, Marina Yoshimi. Um estranho no ninho? Padrões privados no Acordo de Barreiras Técnicas ao Comércio da OMC, p. 205.

39 ORGANIZAÇÃO MUNDIAL DO COMÉRCIO. Caso DS458: Australia - (Certain Measures Concerning Trademarks, Geographical Indications and Other Plain Packaging Requirements Applicable to Tobacco Products and Packaging). Disponível em: https://www.wto.org/english/tratop e/dispu_e/cases e/ds458 e.htm. Acesso em 15 set. 2019. 40 ORGANIZAÇÃO MUNDIAL DO COMÉRCIO. Caso DS369: European Communities (Certain Measures Prohibiting the Importation and Marketing of Seal Products). Disponível no site: https://www.wto.org/english/tratop e/dispu e/cases e/ds369 e.htm. Acesso em: 20 out. 2019. 41 ORGANIZAÇÃ̃O MUNDIAL DO COMÉRCIO. DS284: Mexico (Certain Measures Preventing the Importation of Black Beans from Nicaragua). Disponível em: https://www.wto.org/english/tratop_e/dispu_e/cases_e/ds284_e.htm . Acesso em 05 nov. 2019.
} 
YURIE DIAS, Patricia. A relação entre estado e as entidades privadas na regulação do comércio internacional por meio dos regulamentos e padrões privados. Revista Eletrônica Direito e Política, Programa de Pós-Graduação Stricto Sensu em Ciência Jurídica da UNIVALI, Itajaí, v.16, n.1, ${ }^{0}$ quadrimestre de 2021. Disponível em: www.univali.br/direitoepolitica - ISSN 1980-7791

para o tabaco eram inconsistentes com o Art. 2.2. do Acordo TBT no sentido de que as medidas restringiam o comércio mais do que o necessário para atingir os objetivos legítimos das medidas. Dessa forma, em 28/08/2018, o Relatório foi adotado e nenhuma ação precisou ser tomada. Percebe-se que nesse caso o painel entendeu que as medidas australianas não tinham finalidade de criar obstáculos técnicos ao comércio, mas sim buscavam um objetivo legítimo, por isso, estavam em conformidade com o disposto no TBT.

No caso DS369, em 25/09/2007, o Canadá consultou a Comunidade Europeia acerca de certas medidas adotadas pela Bélgica e a Holanda para os produtos derivados de foca e se o requerimento de licença de importação violava às regras do GATT e do TBT. Em 11/02/2011, o Canadá solicitou o estabelecimento de painel da OSC. Contudo, em 01/12/2014, o Canadá informou ao OSC que as medidas questionadas foram revogadas, por isso, o caso foi encerrado. Percebe-se que nesse caso, apesar do painel não ter se manifestado, as partes chegaram a um acordo.

No caso DS284, em 17/03/2003, a Nicarágua consultou o México acerca de certas medidas adotadas na importação de feijão preto como requerimentos fitossanitários estabelecidos pelos padrões privados Official Standard 006-FITO-95 e Official Standard 028-FITO-95, pois tais medidas eram inconsistentes com o GATT e Acordo SPS. Contudo, em 08/03/2004, a Nicarágua informou ao OSC que as medidas questionadas foram revogadas e o caso foi encerrado. Percebe-se que nesse caso, apesar do painel não ter se manifestado, as partes chegaram a um acordo, diante da revogação das medidas.

Em outro sentido, no caso Japan-Semicondutores (1998) foi comprovado envolvimento do governo nas medidas privadas, violação do GATT (art. X, 1). Na disputa, as Comunidades Europeias questionaram as restrições voluntárias às exportações impostas pela indústria japonesa contra as exportações de semicondutores para os EUA. O Japão argumentou que a medida era proveniente do setor privado e, portanto, não passível de questionamento no âmbito do GATT. O Painel discordou e concluiu que uma estrutura administrativa havia sido criada pelo governo japonês, a qual exercia pressão suficiente para que o setor privado 
YURIE DIAS, Patricia. A relação entre estado e as entidades privadas na regulação do comércio internacional por meio dos regulamentos e padrões privados. Revista Eletrônica Direito e Política, Programa de Pós-Graduação Stricto Sensu em Ciência Jurídica da UNIVALI, Itajaí, v.16, n.1, ${ }^{0}$ quadrimestre de 2021. Disponível em: www.univali.br/direitoepolitica - ISSN 1980-7791

não exportasse a preços baixos. O Painel considerou que a existência de um sistema formal de controle de exportação, apesar da ausência de obrigações formalmente vinculantes. Assim, o Painel concluiu que existia o caráter mandatório dos requisitos estabelecidos pelo governo japonês. Dessa forma, as restrições voluntárias e privadas à exportação de semicondutores foram atribuídas ao Japão e o Painel concluiu que o Japão violou o artigo XI:1 do GATT ${ }^{42}$.

No caso EC-Abestos (2001) a medida de proibição imposta a fibras de amianto por saúde pública foi considerada regulamento técnico, pois foi aplicada para um grupo identificável. O Órgão de Apelação analisou que a proibição imposta a fibras de amianto por motivos de saúde pública poderia ser enquadrada como "regulamento técnico" segundo o TBT. Neste caso, a OSC estabeleceu-se 3 etapas para verificar quando uma medida se encaixa no conceito de regulamento técnico: 1) medida deve ser aplicável a um produto ou grupo de produto identificável; 2) medida deve estabelecer características para produtos e 3) medida ser obrigatória ${ }^{43}$.

Diante dos casos apresentados, depreende-se que a responsabilidade do Estado frente às regras da OMC no que tange a imposição de padrões privados pode ser direta ou indireta. Em alguns casos ficou demonstrado que a própria parte demandada revogou as medidas questionadas, demonstrando os interesses das partes em se buscar o acordo mútuo.

Em que pese as regras multilaterais da OMC ter definições vagas e imprecisas, principalmente, com relação a adoção de padrões privados pelos membros, nos casos submetidos à OSC percebe-se que o órgão, ao analisar os casos, verifica se as medidas adotadas são "medidas governamentais", se há "suficiente envolvimento do governo" e se o governo adotou as "medidas razoáveis a seu alcance" para evitar obstáculos ao comércio internacional.

O objetivo da OMC é evitar que os membros se esquivem das regras multilaterais por meio das entidades privadas que realizam os objetivos políticos e sociais dos

\footnotetext{
42 AMARAL, Manuela. Padrões Privados e a Atuação ou Omissão do Estado: Protecionismo Público-Privado?, p. 406.

43 AMARAL, Manuela. Padrões Privados e a Atuação ou Omissão do Estado: Protecionismo Público-Privado?, p. 406.
} 
YURIE DIAS, Patricia. A relação entre estado e as entidades privadas na regulação do comércio internacional por meio dos regulamentos e padrões privados. Revista Eletrônica Direito e Política, Programa de Pós-Graduação Stricto Sensu em Ciência Jurídica da UNIVALI, Itajaí, v.16, n.1, ${ }^{0}$ quadrimestre de 2021. Disponível em: www.univali.br/direitoepolitica - ISSN 1980-7791

governos. Dessa forma, constatou-se que o OSC, primeiro, apura se há vinculação entre a atuação dos entes privados com o governo. Depois, se não houver vinculação entre esses entes, o órgão analisa se os governos adotaram as "medidas razoáveis" ao seu alcance para o cumprimento do Código de Boa Conduta do art. 4.1. do TBT.

Diante do exposto, entende-se que os regulamentos e os padrões privados podem sim complementar as regras multilaterais do comércio com o intuito de garantir maior segurança e qualidade dos produtos, bem como preservar o meio ambiente, promover a sustentabilidade e proteger a saúde humana, animal e vegetal, promovendo o comércio entre os países.

\section{CONSIDERAÇÕES FINAIS}

O comércio internacional tem sido marcado pela presença de regulamentos e padrões privados formulados por governos ou entes não estatais com o objetivo de aumentar a segurança e qualidade dos produtos, promover a sustentabilidade, além de proteger os direitos humanos e o meio ambiente, como pode ser visto nos seguintes padrões privados: Codex, ISO, United Nations Global Compact e Processo Kimberley.

A OMC é uma organização internacional que visa promover a liberalização do comércio e eliminar a discriminação do comércio, mas também busca proteger a vida humana, animal e vegetal, bem como proteger o meio ambiente por meio do desenvolvimento sustentável. Nesse sentido, constata-se que os regulamentos e padrões privados podem complementar as regras multilaterais da OMC tendo em vista que fornecem regras mais claras para os processos de produção e produtos, além que estabelecerem padrões mínimos de segurança, qualidade dos produtos e proteção da saúde humana, animal e vegetal, complementando assim o disposto no GATT, Acordo TBT e Acordo SPS.

Contudo, diante da análise de alguns casos submetidos à OMC, observou-se que o tema central era o questionamento acerca de certas medidas adotadas pelos 
YURIE DIAS, Patricia. A relação entre estado e as entidades privadas na regulação do comércio internacional por meio dos regulamentos e padrões privados. Revista Eletrônica Direito e Política, Programa de Pós-Graduação Stricto Sensu em Ciência Jurídica da UNIVALI, Itajaí, v.16, n.1, ${ }^{0}$ quadrimestre de 2021. Disponível em: www.univali.br/direitoepolitica - ISSN 1980-7791

membros supostamente estariam restringindo o comércio internacional, criando barreiras desnecessárias ao comércio como se fossem verdadeiras medidas protecionistas a produção local.

Após a análise dos casos, verificou-se que tal afirmação não foi comprovada, pois os casos tiveram desfechos diferentes. Em dois casos os demandados, voluntariamente, revogaram as medidas questionadas, encerrando o dissídio (DS369: Comunidades Europeias-Foca e DS284: México-Feijão Preto). Em outros casos, os governos foram responsabilizados pelas medidas incompatíveis com as regras da OMC, pois tais medidas foram consideradas como sendo regulamentos do governo (Japan-Semicondutores-1998 e EC-Abestos-2001). No último caso, o governo não foi responsabilizado pelas medidas, pois não criavam obstáculos ao comércio (DS458: Austrália-Tabaco). Conclui-se então que os regulamentos e padrões privados podem sim complementar as regras da OMC, desde que eles visem aos objetivos propostos e não sejam medidas protecionistas disfarçadas para favorecer determinado mercado ou país.

\section{REFERÊNCIAS DAS FONTES CITADAS}

AMARAL, Manuela. Padrões Privados e a Atuação ou Omissão do Estado: Protecionismo Público-Privado? Contexto Internacional (PUC), Rio de Janeiro, v. 37, n. 2, mai/ago. 2015.

AMARAL, Manuela. Protecionismo privado: a atuação da sociedade civil na regulação do comércio internacional. Contexto Internacional (PUC), Rio de Janeiro, v. 36, n. 1, jan/jun. 2014.

BADIN, Michelle Ratton Sanchez; TAKITANI, Marina Yoshimi. Um estranho no ninho? Padrões privados no Acordo de Barreiras Técnicas ao Comércio da OMC. Revista de Direito Internacional, Brasília, v. 13, n. 3, 2016 
YURIE DIAS, Patricia. A relação entre estado e as entidades privadas na regulação do comércio internacional por meio dos regulamentos e padrões privados. Revista Eletrônica Direito e Política, Programa de Pós-Graduação Stricto Sensu em Ciência Jurídica da UNIVALI, Itajaí, v.16, n.1, ${ }^{0}$ quadrimestre de 2021. Disponível em: www.univali.br/direitoepolitica - ISSN 1980-7791

BARRAL, Welber. Solução de controvérsias na OMC. In: KLOR et al. Solução de Controvérsias: OMC, União Europeia e Mercosul. Rio de Janeiro: KonradAdenauer-Stiftung, 2004.

BOSSCHE, Peter Van Den. Curso de Solução de Disputas em Comércio Internacional, Investimentos e Propriedade Intelectual. Nações Unidas: Conferência das Nações Unidas sobre Comércio e Desenvolvimento (UNCTAD), 2003.

BRASIL. Agência Nacional de Mineração. Disponível em: http://www.anm.gov.br/assuntos/ao-minerador/certificado-do-processo-dekimberley Acesso em: 12 abr. 2020.-

BRASIL. Ministério da Economia. Acordo SPS. Disponível em: http://www.mdic.gov.br . Acesso em: 20 mar 2020.

ISO. Disponível em: https://www.iso.org/home.html . Acesso em: 17 abr. 2020.

JACKSON, John Howard. The world trading system: law and policy of international economic relations. 2. ed. Cambridge: MIT Press, 1997.

KOLIEB, Jonathan. When to Punish, When to Persuade and When to Reward: Strengthening Responsive Regulation with the Regulatory Diamond. Monash University Law Review, 2015.

MAVROIDIS, Petros C. e WOLFE, Robert. Private Standards and the WTO: Reclusive No More. EUI Working Paper RSCAS 2016/17. European University Institute. Robert Schuman Centre for Advanced Studies. Global Governance Programme. 2016.

ORGANIZAÇÃO DAS NAÇÕES UNIDAS. Disponível em: https://www.unglobalcompact.org/ Acesso em: 12 abr. 2020.

ORGANIZAÇÃO MUNDIAL DO COMÉRCIO. Disponível no site: https://www.wto.org. Acesso em: 20 out. 2019. 
YURIE DIAS, Patricia. A relação entre estado e as entidades privadas na regulação do comércio internacional por meio dos regulamentos e padrões privados. Revista Eletrônica Direito e Política, Programa de Pós-Graduação Stricto Sensu em Ciência Jurídica da UNIVALI, Itajaí, v.16, n.1, ${ }^{0}$ quadrimestre de 2021. Disponível em: www.univali.br/direitoepolitica - ISSN 1980-7791

PIFFER, Carla. Comércio Internacional e Meio Ambiente: A Organização Mundial do Comércio como locus de governança ambiental. Veredas do Direito, Belo Horizonte, v.8, n.15, Jan/Jun. 2011.

PROCESSO KIMBERLEY. Disponível em: https://www.kimberleyprocess.com/en/what-kp Acesso em: 12 abr. 2020.

THORSTENSEN, Vera. A OMC - Organização Mundial do Comércio e as negociações sobre comércio, meio ambiente e padrões sociais. Rev. Bras. Polít. Int. 41 (2): 29-58, 1998.

THORSTENSEN, Vera; KOTZIAS, Fernanda. Barreiras Regulatórias: um novo desafio para a governança da OMC. Centro de Estudos do Comércio Global e Investimentos EESP/FGV, 2015.

UNITED NATIONS GLOBAL COMPACT. Disponível em:

https://www.unglobalcompact.org/ Acesso em: 12 abr. 2020.

RECEBIDO EM: ABR/2020

APROVADO EM: SET/2020 